\title{
Development of THE Canadian EngineEring Ethics GaMe: FEEDBACK FROM PROFESSIONAL ENGINEERS
}

\author{
Andrew Roncin \\ Red River College \\ aroncin@ rrc.ca
}

\begin{abstract}
Researchers at the University of Manitoba developed a prototype video game to assess the question, could Engineering Ethics in Canada be effectively taught using a video game. Based on the feedback of twenty professional engineers and engineering interns who play tested the game, the method is valid and worthy of future work. This paper breaks down the specific feedback given and the considerations for improvement that resulted.
\end{abstract}

Keywords: Engineering Education Methods, Engineering, Ethics, Professional Practice, Digital GameBased Learning, Canada, CEAB, Engineering Interns, Engineering Licensure

\section{INTRODUCTION}

Engineering ethics is an important aspect of undergraduate education and professional registration [1] [2] [3] [4] [5] [6] [7]. However, there exists a large gap between a theoretical understanding the engineering Code of Ethics and the context of professional practice [8] [9] [10] [11] [12]. Based on the principals of experiential and authentic learning, researchers at the University of Manitoba developed a video game featuring non-linear dialogue to create a more authentic learning environment.

The goal of this project was to assess whether Digital Game-Based Learning (DGBL) [13] [14] [15] [16] [17] could be effective for teaching Canadian engineering ethics. A peer review by twenty practicing engineers and engineering interns was favourable and indicated that the method was valid and further development is worthwhile.

It is important to note that in Manitoba, while most complaints against members are for lack of technical skill, the Act stipulates that engineers in Manitoba must follow the Engineering associations Code of Ethics. Failing to follow the professional behaviours expected of an engineer is grounds to lose one's right to practice.

\section{OVERVIEW}

The Canadian Engineering Ethics Game (CEEG) is a proof of concept prototype built around five case studies of professionalism and ethics in engineering. Each case is designed to encourage players to explore day to day interactions typical of the engineering profession as a whole. The five cases feature decisions around pressures to use illegal software, courting favour, design changes, safety in the workplace, and the value in being registered as an engineer.

Throughout each case, players make ethical decisions and explore the consequences of their choices. Unlike traditional lectures, this method focuses its attention on iterative decision making and evolving consequences, rather than a single decision point with well-defined ethical considerations.

As the game progresses, the player's choices are tracked by six dimensions which their relevance to the Engineers Canada Code of Ethics [5]. Often, decisions will have both positive and negative effects associated with it. These dimensions of professionalism are shown as colored bars in the points section on the right side of Figure 1.

Table 1: Dimensions of Professional Practice

\begin{tabular}{ll}
\hline Dimensions & Guidelines \\
\hline Trust of the public & $1,6,8$ \\
Reputation among one's peers & $3,5,10$ \\
Ability to manage risk & $1,6,8$ \\
Following the Code of Ethics & $5,7,8$ \\
Technical competence & $2,4,6$ \\
Being forthright and fair & $3,5,9$ \\
\hline
\end{tabular}

\section{GAME MECHANICS}

The core mechanic in this game is based loosely on a choose-your-own-adventure novel. Players read a narrative or dialogue on the top of the screen and select one of the responses at the bottom as shown in Figure 1.

For each narrative, up to five responses can exist. 


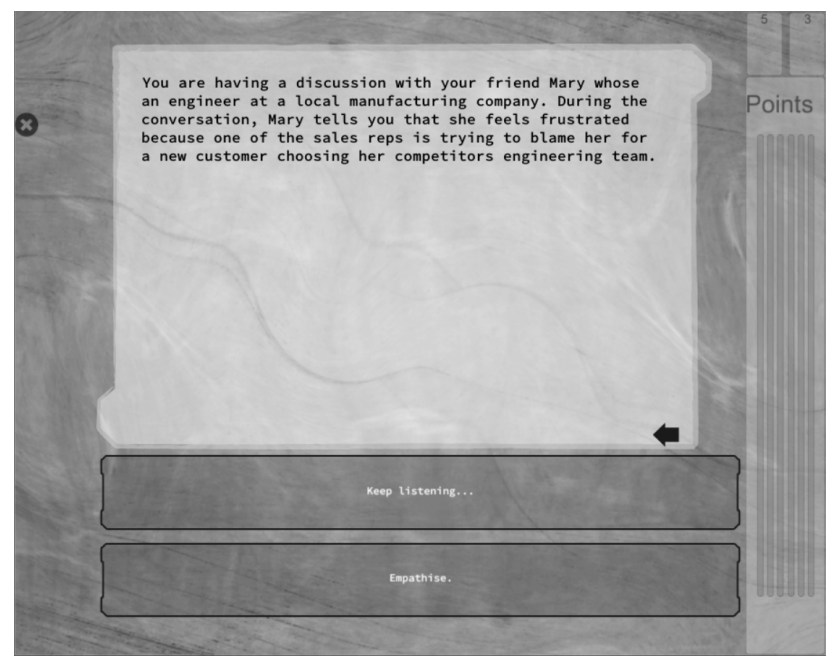

Figure 1: Game Interface

The program consists of 1061 dialogue entries (nodes) with 1307 connections (directed edges) between them. These are grouped into divided into 5 case studies, game control logic, and instructions. Figure 2, shows the structure of a simple section in the "Out to Lunch" case. Play starts at the top of the figure and depending on release conditions and the player's choices they can follow one or more paths through the case. In order to reduce complexity, each section converges into one or more nodes that transition players to other sections of the dialogue (bottom triangle). These transition points also serve as choke points limiting the range of outcomes player's experience.

Figure 3, shows the structure of the question and answer period for the "Out to Lunch" case. The difference in the question and answer sections is that they behave like a multiple choice test, where the responses do not cause divergence in the case, rather just move players on to the next question. Although players found the question and answer sections valuable for causing reflection. They also identified the quantity of questions as making them repetitive, constrained and a source of frustration.

\section{METHODOLOGY}

In order to assess the validity of this approach, Professional Engineers and Engineering Interns were recruited using advertisements in the Engineers Geoscientists Manitoba newsletter. Interested respondents replied to the author, gave their consent and were then given a download key. Once the participants finished playing, they were asked to complete a nine question survey.

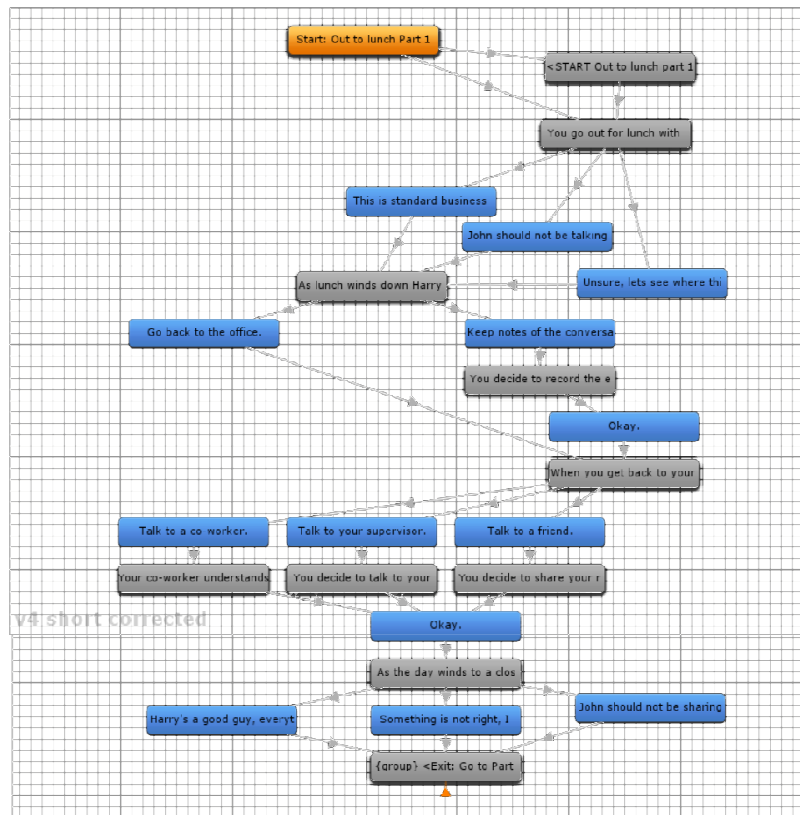

Figure 2: Dialogue structure in one section of a case

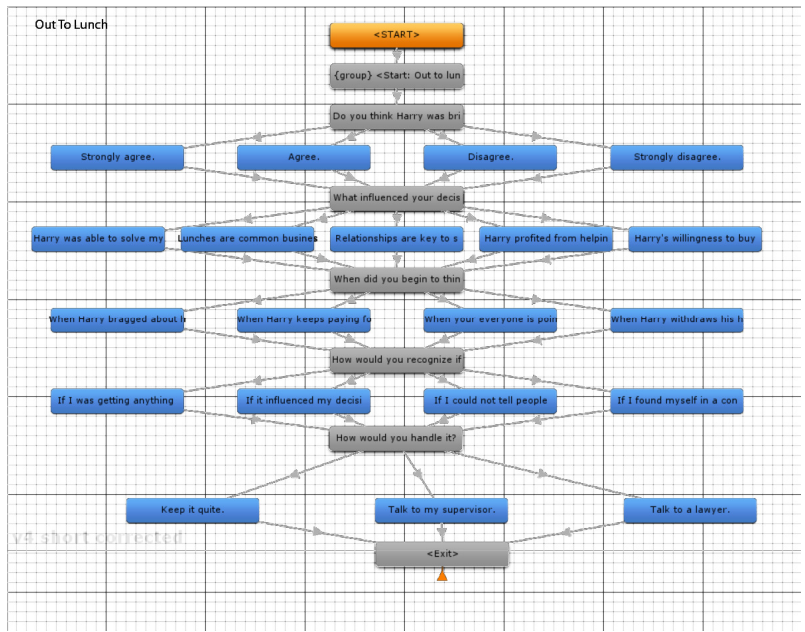

Figure 3: Question and answer structure

The primary purpose of the survey (Table 2) was to evaluate two questions; (1) is this method valid and (2) what improvements need to be made. Questions 1 and 2 were used to qualify participants. Questions $3,4,5$, and 6 were designed to encourage the participants to reflect on the questions and identify if they thought the cases and subsequent questions were realistic, valid, and meaningful. Questions 7, 8, and 9 were used to test the program and identify improvements that could be made going forward.

\section{RESPONSE DEMOGRAPHICS}

The newsletter advertisement was run twice, approximately one month apart in order to secure between 


\section{Table 2: Survey Questions}

\begin{tabular}{|c|c|c|}
\hline & Survey Question & Objective \\
\hline 1 & Are you an engineer? & $\begin{array}{l}\text { Are the participant's engineers, engineering interns, } \\
\text { or members of the public? }\end{array}$ \\
\hline 2 & $\begin{array}{l}\text { Are you familiar with the Act, Bylaws, and Code of } \\
\text { Ethics that govern Engineering in Manitoba? }\end{array}$ & $\begin{array}{l}\text { Are the participant's familiar with the material } \\
\text { covered in this game? }\end{array}$ \\
\hline 3 & In your opinion, do the cases seem realistic? & Are the cases are fundamentally accurate? \\
\hline 4 & $\begin{array}{l}\text { Did the cases cause you think about your } \\
\text { professional responsibility? }\end{array}$ & Is the method valid? \\
\hline 5 & $\begin{array}{l}\text { In your opinion, did the questions and answers make } \\
\text { sense? }\end{array}$ & Is the method valid? \\
\hline 6 & $\begin{array}{l}\text { Did the questions cause you to think more about the } \\
\text { case? }\end{array}$ & Is the method valid? \\
\hline 7 & Are there any glitches in the software? & Identify improvements. \\
\hline 8 & $\begin{array}{l}\text { Do you have any recommendations for } \\
\text { improvement? }\end{array}$ & Identify improvements. \\
\hline 9 & Any other feedback that you feel is valuable? & Identify improvements. \\
\hline
\end{tabular}

10 to 20 fully completed responses. Of the 33 people who expressed interest in trying the game, 30 gave their consent, 20 provided feedback and 16 completed the requested surveys. This number of responses provided enough feedback to see themes in the data and evaluate the program's effectiveness. Three quick observations about the participants are as follows:

- In both cohorts, most of the responses occurred within a few hours of the Engineers Manitoba email newsletter being sent out.

- Of the 16 participants completed the survey, 11 were from the first group and 5 from the second group.

- Given the ads were targeted at engineers, a surprising number of engineering interns responded. Of those who completed the surveys, 11 were engineers and 5 were engineering interns.

\section{FEEDBACK}

This section focuses on the prevailing themes seen in the responses to questions 2 through 9 . In general, the playtesters felt the game was valuable, but were critical and meticulous in identifying areas for improvement. This attention to detail demonstrated good coverage of the game options and reasonably thorough testing.

\subsection{Are You Familiar With The Act, Bylaws, And Code Of Ethics That Govern Engineering In Manitoba?}

\begin{tabular}{|l|c|c|c|}
\hline & Yes & Partial & No \\
\hline Total & 11 & 5 & 0 \\
\hline
\end{tabular}

Of the 16 participants, 5 out of 11 engineers identified that they were partially aware of the Act, Bylaws, and Code of Ethics. All the Engineering interns responded that they were aware of these. Which makes sense given that these are required learning for the National Professional Practice Exam [2].

Of the Professional Engineers who responded that they were somewhat aware of the Act, Bylaws and Code of Ethics, most articulated that they had a passing familiarity with the content. In the words of two Engineers, they were: "Somewhat familiar - it's been years since I read them." and "Mostly. I studied them and know the gist of them, but I do not have them all committed to memory."

\subsection{In Your Opinion, Do The Cases Seem Realistic?}

\begin{tabular}{|l|c|c|c|}
\hline & Yes & Partial & No \\
\hline Total & 9 & 6 & 1 \\
\hline
\end{tabular}


All but one participant felt that the case studies were realistic. However, 5 identified that they had trouble understanding the cases due to a simplified situation and insufficient context. A representative response from one playtester was: "Realistic-ish. I'm sure similar issues come up regularly, but the 'right' and 'wrong' won't usually be so cut and dry. In this case, I understand it has to be relatively obvious, and it can't take too long to arrive at the outcome and questions portion."

\subsection{Did The Cases Cause You Think About Your Professional Responsibility?}

\begin{tabular}{|l|c|c|c|}
\hline & Yes & Partial & No \\
\hline Total & 16 & 0 & 0 \\
\hline
\end{tabular}

All the respondents answered yes to this question. With the two strongest comments being: "The strongest aspect of this game was generating thought about how ethics applies to daily work experience." and "The cases brought forward real issues in our profession. It makes you aware that the issues are not localized but seen through many industries. I commonly think of my responsibility to the public, employer and environment."

\subsection{In Your Opinion, Did The Questions And Answers Make Sense?}

\begin{tabular}{|l|r|r|r|}
\hline & Yes & Partial & No \\
\hline Total & 3 & 12 & 1 \\
\hline
\end{tabular}

This question revealed that the questions after each case were the most important aspect to be improved and represented the key difference between the first and second cohorts. In the first cohort, two sets of questions were in each case, a common set of questions relating to the Act, Bylaws, and Code of Ethics. And a second set related to the case in question. After one playtester described the questions as being stuck in "voicemail hell", the questions about the Act, Bylaws, and Code of Ethics were removed.

Furthermore, the questions at the end of each case had not yet been tied to the specific paths the players had taken, resulting in several participants feeling they were being asked questions about problems they had not encountered.

\subsection{Did The Questions Cause You To Think More About The Case?}

\begin{tabular}{|l|c|c|c|}
\hline & Yes & Partial & No \\
\hline Total & 11 & 3 & 2 \\
\hline
\end{tabular}

Playtesters generally responded yes to this question, but of those who gave a more verbose response, identified that the first set of questions got them thinking about the case, but when those questions were repeated, they added little value. Overall, the feedback revealed that the questions were an essential part of the thinking and reflection process and need to be carefully considered in order to cause meaningful reflection.

\subsection{Are There Any Glitches In The Software?}

\begin{tabular}{|l|c|c|c|}
\hline & Yes & Partial & No \\
\hline Total & 16 & 0 & 0 \\
\hline
\end{tabular}

Being a prototype, there were many glitches in the software. The two most frustrating for the participants were grammar and events that caused the game to lock up.

\subsection{Do You Have Any Recommendations For Improvement?}

\begin{tabular}{|l|c|c|c|}
\hline & Yes & Partial & No \\
\hline Total & 13 & 0 & 2 \\
\hline
\end{tabular}

Three general recommendations emerged for improvement the program. The first was to clarify the specific text in certain nodes, ensuring that the players could understand and predict the consequences of their choices. The second recommendation was to include more divergent options so that players could find alternative solutions to the problems presented. The third recommendation was to provide better feedback to players throughout the game. Many playtesters found the points bar to simplistic and would have preferred contextual feedback on how their decisions related back to the Act, Bylaws and Code of Ethics.

\subsection{Any Other Feedback That You Feel Is Valuable?}

\begin{tabular}{|l|c|c|c|}
\hline & Yes & Partial & No \\
\hline Total & 13 & 0 & 1 \\
\hline
\end{tabular}

In this question, many of the playtesters added their unique feedback on the game. Improvements they recommended included changing the point structure, increasing feedback, adding more references to specific clauses in the Act, Bylaws, and Code of Ethics, and fine tuning the cases.
CEEA17; Paper 030

University of Toronto; June 4-7, 2017

$$
-4 \text { of } 6-
$$




\subsection{Additional Feedback:}

A general theme from the playtesters was that the concept was good, the scenarios were realistic and valuable, and that the game had merit. The following are three comments taken from the participant feedback.

"Overall I thought the scenarios were much more applicable as compared to the standard testing from the PPE exam. Issues like software piracy and advanced simulation is a more modern approach for sure."

"The situations and detail in this game are very interesting. I believe you have selected a set of situations that is somewhat representative across the engineering profession. The 6 parameters with regards to the qualities to be maximized by an engineer highlight an appreciation for complexity in the profession as advancing one parameter can reduce another."

"I think the scenarios are good. I like the scenario with the sales team pressuring engineers to do things. It is a very common issue, where managers and sales groups pressure engineers to do things they are uncomfortable with. There is always a way to do business with ethical business practices, it is just up to the leadership to set that tone."

\section{LESSONS LEARNED}

The key lesson learned developing this game is that thinking about ethics cannot be done in isolation. There are many perspectives, values, and experiences that come into play when deciding what course of action to take.

Through the feedback of the playtesters, discussions Engineers Geoscientists Manitoba staff, and discussions

\section{REFERENCES}

[1] Engineers Canada, "Canadian Engineering Accreditation Board: 2016 Accreditation Criteria and Procedures," Engineers Canada, Ottawa, 2016.

[2] Association of Professional Engineers and Geoscientists of Alberta, "National Professional Practice Exam," [Online]. Available: https://www.apega.ca/apply/exams/nppe/.

[Accessed 8 May 2107].

[3] Association of Professional Engineers and Geoscientists of the Province of Manitoba (APEGM), "Code of Ethics for the Practice of Professional Engineering \& Professional Geoscience," Winnipeg, MB, 2000. with members of the investigation and discipline committees, these cases grew and evolved to become a dynamic set of interactions that more authentically represent professional practice than a traditional one decision, one correct course of action case study.

The second lesson learned is that it is very important to provide cues for playtesters to uniquely identify any point in the game. Between the first and second cohorts, a display of the current dialogue node was added. This simple change made a substantial difference in the quality of error reports submitted and allowed me to more easily track and reproduce the errors.

The final lesson learned was to simplify the testing interface as much as possible. Between the first and second cohort, several problematic controls were disabled making the software more reliable. This cause playtesters in the second cohort to be less frustrated and focus more on the narrative and gameplay.

\section{CONCLUSION}

Developing a game in which the "right answers" vary based on the path is challenging. It requires consideration of what an authentic learning experience should look like, developing a game mechanic that builds skills valuable in the real work. It also requires good testing to deal with the complexity and interconnectedness of the answers.

Through their feedback, the playtesters confirmed that this method is valid, worthwhile and worthy of future research.

[4] Engineers Canada, "Good Character Guide," 2012. [Online]. Available: https://engineerscanada.ca/sites/default/files/guide line_good_character.pdf. [Accessed 1 May 2017].

[5] Engineers Canada, "Guideline on the Code of Ethics," Engineers Canada, Ottawa, 2012.

[6] Professional Engineers Ontario, "Discipline," [Online]. Available: http://www.peo.on.ca/index.php?ci_id=1823\&la_i $\mathrm{d}=1$. [Accessed 2 May 2017].

[7] Professional Engineers Ontario, "Professional Engineering Practice," 2012. [Online]. Available: http://www.peo.on.ca/index.php/ci_id/22127/la_i d/1.htm. [Accessed 2701 2015].

[8] A. Roncin, R. Britton and G. Koropatnick, "Professional Practice and Engineering Interns: Three Cases for Discussion," in Proc. 2017 Canadian Engineering Education Association (CEEA17) Conf., Toronto, 2017. 
[9] W. T. Lynch and R. Kline, "Engineering Practice and Engineering Ethics," Science, Technology \& Human Values, vol. 25, no. 2, pp. 195-225, 2000.

[10] L. L. Bucciarelli, "Ethics and engineering education," European Journal of Engineering Education, vol. 33, no. 2, pp. 141-149, 2008.

[11] T. Rieder, "AC 2008-1159: Ethical Theory for Engineers: Avoiding Caricature and Informing Intuitions," in American Society for Engineering Education Annual Conference and Exposition 2008, Pittsburgh, Pennsylvania, USA, 2008.

[12] J. A. Hamad, M. Hasanain, M. Abdulwahed and R. Al-Ammari, "Ethics in Engineering Education: A literature review," in 2013 IEEE Frontiers in Education Conference (FIE), Oklahoma City, 2013.

[13] S. Egenfeldt-Nielsen, "Third Generational Educational Use of Computer Games," Journal of Educational Multimedia and Hypermedia, vol. 16, no. 3, pp. 263-281, 2007.
[14] K. Schrier, "Learning, Education and Games. Volume One: Curricular and Design Considerations," ETC Press, Pittsburgh, 2014.

[15] S. A. Barab, M. Gresalfi and A. Arici, "Why Educators Should Care About Games," Educational Leadership, 092009.

[16] R. Van Eck, "Digital Game-Based Learning: It's Not Just the Digital Natives Who Are Restless....," Educause review, vol. 41, no. 2, 2006.

[17] R. Van Eck, "Digital Game-Based Learning: Still Restless, After All These Years," 2015. [Online]. Available: http://er.educause.edu/articles/2015/10/digitalgame-based-learning-still-restless-after-all-theseyears. [Accessed 12 December 2016]. 